\title{
Prevalence of intestinal protozoan infection among patients in Hawassa city administration millennium health center, Ethiopia
}

\begin{abstract}
Current retrospective study was carried out from April to May, 2009 E.C. to determine the prevalence of intestinal protozoan parasitic infection in Hawassa city administration millennium health center from 2004-2008 E.C. From the study, a total of 89423 peoples of both males and females were examined for various intestinal protozoan parasitic infection test. From these 39895(44.61\%) were positive to intestinal protozoan parasitic infection. The study shows that, Entamoeba histolytica and Giardia lambila were the most common intestinal protozoan parasitic infections among patients. Between these, Entamoeba histolytica was highly prevalent $(57.53 \%)$ and Giardia lambila was the next prevalent $(42.47 \%)$ intestinal protozoan parasitic infections. With over all age association the most infected age groups were less than 10 years old $(22.98 \%)$ and the least affected age groups were greater than 50 years old peoples $(16.75 \%)$. And the most infected sex groups were males $(50.98 \%)$ and the less infected sex groups were females $(49.02 \%)$. According to the current study the infection of intestinal protozoan such as: Entamoeba histolytica/dispar and Giardia lambila were highly distributed in Hawassa city administration millennium health center. So, to minimize or inhibit the spread and impact of its infection all community members should get awareness for proportion of personal and environmental hygiene and this should be the responsibility of all individuals.
\end{abstract}

Volume 5 Issue 4 - 2018

\author{
Beyene Dobo \\ Hawassa University, Ethiopia
}

Correspondence: Beyene Dobo, Hawassa University, College of Natural and Computational Sciences, P.O.Box: 05, Hawassa, Ethiopia,Email beyeneashl@yahoo.co.uk

Received: March 30, 2018 | Published: July 17, 2018

Keywords: intestinal protozoa infection, distribution of intestinal protozoa, hawassa city administration millennium health center, patient

\section{Introduction}

Intestinal protozoa are single celled eukaryotic microorganisms belonging to animal kingdom. There are greater than 20,000 named species of protozoa, from those nearly 10,000 species are parasitic in invertebrates and almost all vertebrates. It estimates that as much as $60 \%$ of the world population is infected with intestinal parasites, which may play a significant role in morbidity due to intestinal infection. Intestinal protozoa parasitic infections are among the most common worldwide. It estimate that some 3.5 billion people are affected and 450 million ill as a result of these infection. ${ }^{1}$

Intestinal protozoa are parasites that populate the gastrointestinal tract in human and other animals. A parasitic protozoan is an organism that feeds on other organisms that means hosts. Each of these intestinal parasitic protozoa can infect the digestive tract and sometime can cause two more infection at the same time. Intestinal protozoan parasites can get into intestine by going through the mouth from uncooked or unwashed food, contaminated water or milk. When the organisms are swallowed they move into intestine, where they can reproduce and cause symptoms. ${ }^{2}$

Intestinal protozoa parasitic infections are the major disease of public health problem throughout the world. Some of the parasitic species responsible are associated with severe morbidity after resulting in mortality particularly, in developing tropical and subtropical countries. Amoebiasis, Giardasis and other protozoan species like trichuriasis are among the most common intestinal protozoa parasitic species worldwide and are closely related to socioeconomic status, poor sanitation, inadequate medical care and absence of safe drinking water supplies. ${ }^{3}$

Intestinal protozoa can cause serious and even fatal condition in human and animals. Various types of intestinal protozoa can inhabit in human and those have a range of symptoms of different severities. Symptoms of the different intestinal protozoa may include diarrhea, stomach pain, nausea or vomiting, boating, liver abscesses, colitis and feeling of tired. It is important to understand the source and prevention strategies of intestinal protozoa in order to combat this potentially serious condition. ${ }^{4}$

Giardia lambila is intestinal protozoa that infect a wide array of vertebrates, including humans, pests, live stocks, wild life and marine animals. Giardia lambila has a global distribution and is one of the most common diarrhea related parasites in human, where infection ranges from asymptomatic to symptomatic involving both acute and chronic disease. According to estimate about 200 million people worldwide have symptoms of intestinal Giardiasis and 500,000 new cases occur annually due to its impact on health on especially among children in developing countries. Giardia has been included in the neglected diseases initiative of the world health organization. ${ }^{3}$

Thus the aim of this study is to determine the prevalence of intestinal protozoa infection in Hawassa city administration millennium health center and to give appropriate suggestion for the society how to prevent themselves from its infection and also to identify the factors which contribute for the intestinal protozoa infection.

\section{Materials and methods}

\section{Study area description}

The study was conducted around millinume health center found in Hawassa. Hawassa city is the administrative center of sidama zone as well as the seat of the Southern Nations nationalities and Peoples Regional state of Ethiopia. It is located about $275 \mathrm{~km}$ from Addis Ababa which is the capital city of Ethiopia. The city is bounded by Lake Hawassa in the West, Oromia region in the North, Wondo 
Genet woreda in the East and Shebedino woreda in the South and the topography feature is level (flat) and bounded by some mountains like Alamura, Tabor and so on. The major socio-economic of populations are industrial, commercial and Agricultural sector. The overall agriculture sector comprises of crops, livestock, fisheries, and forestry sub sectors. Most of the farming is conducting in HawellaTulla sub-city, but urban agriculture is also practiced in all sub-cities. Geographically the city is located between $6^{\circ} 54^{\prime}$ latitude $\mathrm{N}$ and $38^{\circ} 48^{\prime}-38^{\circ} 33^{\prime}$ longitude E. ${ }^{5}$

The city is situated within latitude and longitudes of $6 \mathrm{~N}$ and $38 \mathrm{E}$ respectively or lies at the altitude ranges from $(1,500$ to 3,500$)$ meters above sea levels. The mean annual rainfall and temperature of the area varies from $800-1000 \mathrm{~mm}$ and $20.1^{\circ} \mathrm{C}-25^{\circ} \mathrm{C}$ respectively. According to the of Housing and population census of May 2007 current population of Hawassa is estimated about 258,808 people, out of whom 133,123 are males and 125,685 are females. While 157,879 or $61 \%$ are living in the city of Hawassa, the rest of population of this zone is living at surrounding rural kebeles. A total of 61,279 households were counted in this zone, which results in an average of 4.22 persons to a household, and 57,469 housing unit with the annual population growth rate of $4.02 \%$ (CSA, 2007). ${ }^{7}$ Hawassa is center for high level education and training in the region.

\section{Study design}

Retrospective study design was conducted to describe and analyze the prevalence of intestinal protozoa among patients from 2004-2008 E.C in Hawassa city administration millennium health center. Secondary source of data from Hawassa city administration millennium health center parasitic patient registered book.

\section{Study population}

The source of information of this study was all patients with intestinal protozoa infection who attended care and treatment in Hawassa city administration millennium health center from 20042008 E. C.

\section{Data collection methods}

The data was collected from Hawassa city administration millennium health center using secondary data. Secondary data was taken from parasitic patient registered book of millennium health center laboratory. The data included in this study range from 2004 2008 E.C.

\section{Data analysis method}

After collection of data, it was analyzed by using descriptive statistics; which deals with descriptive characteristic of set of statistical data by the method of organizing, presenting and analyzing by using: table, percentage, frequency and graph. The study also used proportions to compare different age group and sex of people affected with intestinal protozoa infection in Hawassa city administration millennium health center.

\section{Result}

A total of 89423 peoples of both sexes males and female were examined to test intestinal protozoa parasitic infection in Hawassa city administration millennium health center from 2004-2008 E.C. From those peoples, 49712(55.59\%) were males and 39711(44.40\%) were females. Out of 89423 peoples examined 39895 (46.61\%) were positive to intestinal protozoan infections (Table 1). The result of present study show that, the most commonly distributed protozoan parasitic infections, which identified were Entamoeba histolytica, 22951(57.53\%) and Giardia lambila, 16944 (42.47\%) (Table 2).

Table I Overall distribution of intestinal protozoan infections in Hawassa city administration, millennium health center from 2004- 2008 E.C

\begin{tabular}{lll}
\hline Year & $\begin{array}{l}\text { No. of positive to } \\
\text { intestinal protozoa }\end{array}$ & $\begin{array}{l}\text { No. of total } \\
\text { examined peoples }\end{array}$ \\
\hline 2004 & $40.59 \%$ & $25.97 \%$ \\
2005 & $45.47 \%$ & $22.28 \%$ \\
2006 & $47.54 \%$ & $14.93 \%$ \\
2007 & $51.15 \%$ & $18.13 \%$ \\
2008 & $44.61 \%$ & $18.59 \%$ \\
Total & $44.61 \%$ & $100 \%$ \\
\hline
\end{tabular}

Table 2 Prevalence of intestinal protozoan parasitic infection in Hawassa city administration millennium health center from 2004 to, 2008 E.C

\begin{tabular}{llll}
\hline \multirow{2}{*}{ Year } & \multicolumn{3}{l}{ Types of intestinal protozoan parasites } \\
\cline { 2 - 4 } & E. histolyitca & G. lambila & Total distribution \\
\hline 2004 & $57 \mid 4(60.60 \%)$ & $37 I 5(39.39 \%)$ & $9429(23.69 \%)$ \\
2005 & $505 I(56.06 \%)$ & $4012(44.26 \%)$ & $9063(22.72 \%)$ \\
2006 & $3674(57.83 \%)$ & $2674(42.12 \%)$ & $6348(15.91 \%)$ \\
2007 & $4650(53.82)$ & $3681(44.18 \%)$ & $8331(20.88 \%)$ \\
2008 & $3862(57.44 \%)$ & $2862(42.56 \%)$ & $6724(16.85 \%)$ \\
Total & $22951(57.53 \%)$ & $16944(42.47 \%)$ & $39895(100 \%)$ \\
\hline
\end{tabular}

From all age associated distribution, 9071(22.98\%) were less than 10 years old, 8176(20.49\%) were ranging from 11-20 years old, $8610(21.58 \%)$ were ranging from 21-35years old, $7259(18.19 \%)$ were reneging from $36-50$ years old and $6682(16.75 \%)$ were greater than 50 years old (Table 3 ). Based on the age associated distribution, the infection was highly distributed in children whose age less than ten years old. Its distribution was $(22.98 \%)$ with intestinal protozoan parasitic infection than the other age groups. And the least infected age groups were greater than fifty years old $(16.75 \%)$.

Table 3 Age associated distribution of intestinal protozoan infection in Hawassa city administration millennium health center from 2004-2008E.C

\begin{tabular}{lllll}
\hline \multirow{2}{*}{ Year } & Age & \multicolumn{3}{c}{ Types of intestinal protozoan } \\
\cline { 3 - 5 } & & E. histolytica & G. lambilia & Total \\
\hline \multirow{2}{*}{2004} & Less than 10 & $23.46 \%$ & $22.69 \%$ & $23.16 \%$ \\
& $20-N o v$ & $20.37 \%$ & $20.43 \%$ & $20.39 \%$ \\
& $21-35$ & $21.78 \%$ & $21.88 \%$ & $21.82 \%$ \\
& Greater than 50 & $16.87 \%$ & $17.73 \%$ & $17.59 \%$ \\
& Total & $100 \%$ & $17.25 \%$ & $17.02 \%$ \\
& Less than 10 & $24.74 \%$ & $100 \%$ & $100 \%$ \\
& $20-N o v$ & $21.40 \%$ & $19.79 \%$ & $20.68 \%$ \\
& $21-35$ & $22.62 \%$ & $20.96 \%$ & $21.89 \%$ \\
& $36-50$ & $16.68 \%$ & $18.86 \%$ & $17.65 \%$ \\
& Greater than 50 & $14.53 \%$ & $17.89 \%$ & $16.02 \%$ \\
& Total & $100 \%$ & $100 \%$ & $100 \%$ \\
\hline
\end{tabular}


Table Continued

\begin{tabular}{|c|c|c|c|c|}
\hline \multirow{2}{*}{ Year } & \multirow{2}{*}{ Age } & \multicolumn{3}{|c|}{ Types of intestinal protozoan } \\
\hline & & E. histolytica & G. Iambilia & Total \\
\hline \multirow{6}{*}{2006} & Less than 10 & $22.70 \%$ & $23.70 \%$ & $23.12 \%$ \\
\hline & 20-Nov & $20.08 \%$ & $22.14 \%$ & $20.95 \%$ \\
\hline & $21-35$ & $20.46 \%$ & $22.92 \%$ & $21.50 \%$ \\
\hline & $36-50$ & $19.37 \%$ & $17.46 \%$ & $18.57 \%$ \\
\hline & Greater than 50 & $17.36 \%$ & $13.76 \%$ & $15.84 \%$ \\
\hline & Total & $100 \%$ & $100 \%$ & $100 \%$ \\
\hline \multirow{6}{*}{2007} & Less than 10 & $21.97 \%$ & $22.71 \%$ & $22.30 \%$ \\
\hline & 20-Nov & $19.87 \%$ & $21.59 \%$ & $20.63 \%$ \\
\hline & $21-35$ & $20.75 \%$ & $22.06 \%$ & $21.32 \%$ \\
\hline & $36-50$ & $18.96 \%$ & $18.58 \%$ & $18.79 \%$ \\
\hline & Greater than 50 & $18.45 \%$ & $15.05 \%$ & $16.95 \%$ \\
\hline & Total & $100 \%)$ & $100 \%$ & $100 \%$ \\
\hline \multirow{6}{*}{2008} & Less than 10 & $21.87 \%$ & $23.20 \%$ & $22.44 \%$ \\
\hline & 20-Nov & $19.57 \%$ & $19.91 \%$ & $19.72 \%$ \\
\hline & $21-35$ & $21.07 \%$ & $21.42 \%$ & $21.22 \%$ \\
\hline & $36-50$ & $18.97 \%$ & $18.24 \%$ & $18.66 \%$ \\
\hline & Greater than 50 & $18.48 \%$ & $17.23 \%$ & $17.95 \%$ \\
\hline & Total & $100 \%$ & $100 \%$ & $100 \%$ \\
\hline \multirow{6}{*}{ Total } & Less than 10 & $23.06 \%$ & $22.89 \%$ & $22.98 \%$ \\
\hline & 20-Nov & $20.33 \%$ & $20.72 \%$ & $20.49 \%$ \\
\hline & $21-35$ & $21.43 \%$ & $21.78 \%$ & $21.58 \%$ \\
\hline & $36-50$ & $18.17 \%$ & $18.23 \%$ & $18.19 \%$ \\
\hline & Greater than 50 & $17.03 \%$ & $16.37 \%$ & $16.75 \%$ \\
\hline & Total & $100 \%$ & $100 \%$ & $100 \%$ \\
\hline
\end{tabular}

From the study, an overall sex associated distribution of intestinal protozoan parasitic infection was high in males than females. Its distribution was $20339(50.98 \%)$ in males and $19556(49.02 \%)$ in females (Table 4).

Table 4 Sex associated with the prevalence of intestinal protozoan parasitic infections in Hawassa city administration millennium health center

\begin{tabular}{|c|c|c|c|c|}
\hline \multirow{2}{*}{ Year } & \multirow{2}{*}{ Sex } & \multicolumn{3}{|c|}{ Types of intestinal protozoa } \\
\hline & & E. histolytica & G. lambila & Total \\
\hline \multirow{3}{*}{2004} & Females & $2542(45.76 \%)$ & $1918(49.51 \%)$ & $4460(47.30 \%)$ \\
\hline & Males & $30 \mid 3(44.24 \%)$ & $1956(50.49 \%)$ & $4969(52.69 \%)$ \\
\hline & Total & $5555(100 \%)$ & $3874(100 \%)$ & $9429(100 \%)$ \\
\hline \multirow{3}{*}{2005} & Females & $27 \mid 4(49.06 \%)$ & $17 \mid 3(48.51 \%)$ & $4427(48.85 \%)$ \\
\hline & Males & $2818(50.94 \%)$ & $|8| 8(5 \mid .48 \%)$ & $4636(51.15 \%)$ \\
\hline & Total & $5532(100 \%)$ & $3531(100 \%)$ & $9063(100 \%)$ \\
\hline \multirow{3}{*}{2006} & Females & $1854(49.12 \%)$ & $1253(48.68 \%)$ & $3107(48.94 \%)$ \\
\hline & Males & $1920(50.87 \%)$ & $132 \mid(5 \mid .32 \%)$ & $324 I(5 I .05 \%)$ \\
\hline & Total & $3774(100 \%)$ & $2574(100 \%)$ & $6348(100 \%)$ \\
\hline \multirow{3}{*}{2007} & Females & $2368(49.94 \%)$ & $1718(47.85 \%)$ & $4086(49.04 \%)$ \\
\hline & Males & $2373(50.05 \%)$ & $1872(52.14 \%)$ & $4245(50.95 \%)$ \\
\hline & Total & $474 I(100 \%)$ & $3590(100 \%)$ & $8331(100 \%)$ \\
\hline
\end{tabular}

Table Continued

\begin{tabular}{lllll}
\multirow{2}{*}{ Year } & \multirow{3}{*}{ Sex } & \multicolumn{3}{c}{ Types of intestinal protozoa } \\
\cline { 3 - 5 } & & E. histolytica & G. lambila & Total \\
\hline \multirow{2}{*}{2008} & Females & $1888(51.91 \%)$ & $1588(51.44 \%)$ & $3476(51.69 \%)$ \\
& Males & $1749(48.08 \%)$ & $1499(48.55 \%)$ & $3248(48.30 \%)$ \\
& Total & $3637(100 \%)$ & $3087(100 \%)$ & $6724(100 \%)$ \\
& Females & 11366 & $8190(49.17 \%)$ & 19556 \\
Total & Males & $(48.990 \%)$ & $84.02 \%)$ \\
& Total & $(51.09 \%)$ & $8466(50.83 \%)$ & $20339 \%)$ \\
& $23239(100 \%)$ & $16656(100 \%)$ & $39895(100 \%)$ \\
\hline
\end{tabular}

According to this study Entamoeba histolytica was the most predominated intestinal protozoan parasite infection identified in both sex and Guardia labial was the next prevalent intestinal protozoan parasite. Their distributions in Hawassa city administration millennium health center were $58.25 \%$ and $41.75 \%$ respectively (Table 2 ).

Table 1 shows that from the total of 89423 people who were tested for different intestinal protozoa parasite infection from 2004-2008, $39895(44.61 \%)$ are positive to intestinal protozoa parasites.

Table 2 shows According to this study E. histolytica was the most predominated intestinal protozoan parasite infection identified in both sexes and G. lambila was the next prevalent. This distribution in Hawassa city administration millinume health center is (58.25\%) and $41.75 \%$ respectively.

Table 3 shows that from the total of 39895 patients who were infected with different intestinal protozoan infections from 2004 to $2008,(22.98 \%)$ were children whose age ranged from $0-10,(20.49 \%)$ were adolescents whose age ranged from 11-20 years, $(21.58 \%)$ were adults whose age ranged $21-35,(18.23 \%)$ were matured adults whose age ranged from $36-50$ and the remaining $(16.75 \%)$ were old peoples who aged greater than 50 years.

Table 4 shows from the study, an overall sex associated distribution of intestinal protozoan parasite infection was high in males than females its distribution was 20339(50.98\%).

Figure 1 shows the infection was highly distributed in children whose age is less than 10 years old $(22.98 \%)$ and least infected age group were greater than $50(16.75 \%)$.

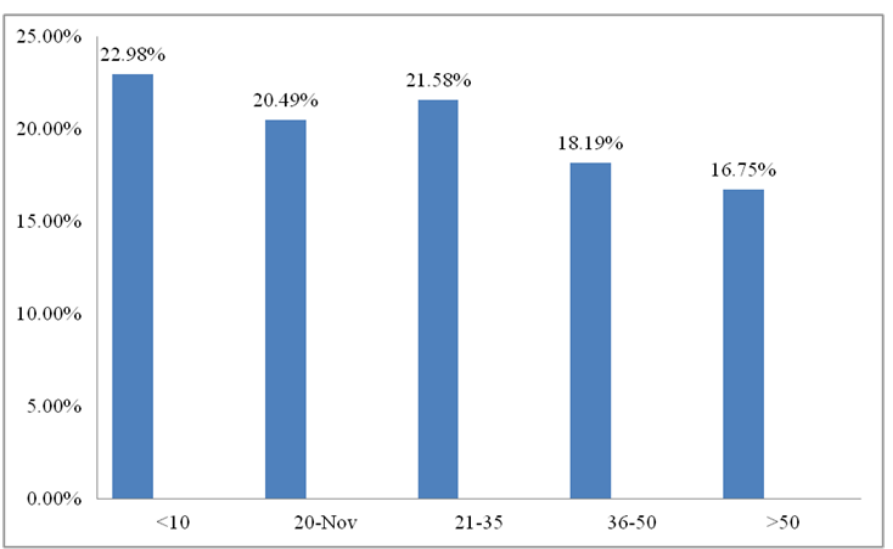

Figure I Age associated distribution of intestinal protozoan parasitic infection.

Figure 2 shows from 2004-2007 male was the most infected sex group than females but in 2008 female are highly infected than male. Generally from 2004-2008 male (50.98\%) are more infected than female $(49.02 \%)$. 


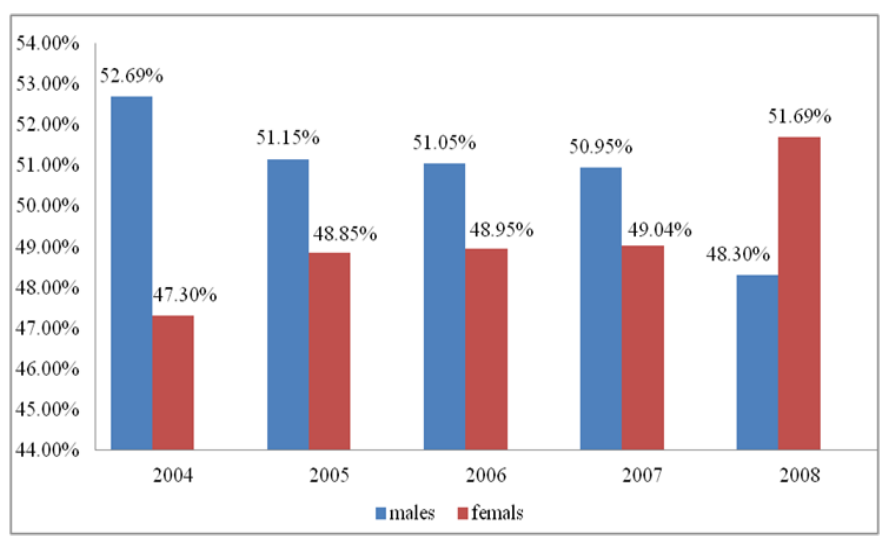

Figure 2 Sex related prevalence of intestinal protozoan parasitic infection.

\section{Discussion}

The present study attempted to assess the prevalence of intestinal protozoan infections in Hawassa city administration millennium health center between 2004 to 2008 E.C. high prevalence of intestinal protozoa parasites infection due to place and living standards of study subject or due to a reflection of the local endemicity and geographic condition of the study area. According to the result of this study, high prevalence of intestinal protozoa parasite's infection observed among children under 10 year age could be due to low immunity in individual, less awareness of washing hands and other personal hygiene measures within this age group. According to the results of this study, females $(49.02 \%)$ had slightly lower infection rate than male (50.98\%) this may be due to the fact that majority of males are more engaged in playing outdoors particularly in fecally contaminated soil, farming, playing football, more frequently than females. Similar observation was made in other studies which suggest that the spread of disease of intestinal protozoan parasite than female. ${ }^{8}$ However, contrary to this ${ }^{9}$ have reported that female was more infected with intestinal protozoan parasite infection than males. In this study $57.53 \%$ and $42.47 \%$ of the patients were positive for E. histolytica and G. lambila, respectively. The high prevalence of intestinal parasites $44.6 \%$ in this study among patients in millennium health center Hawassa Ethiopian was in agreement with the findings of other studies conducted in Ethiopia like Bahir Dar town (41.1\%). ${ }^{10}$ Higher prevalence of intestinal protozoa parasites were reported in Nigeria ${ }^{11}(97 \%)$ when compared with present study, however lower prevalence was reported in North West Ethiopia $(9.2 \%) .{ }^{12}$ The prevalence of E. histolytica $(57.53 \%)$ and G. lambila $(42.47 \%)$ infection in this study was within the range of nationwide prevalence of Amoebiasis and Giardiasis which ranges from $3-55 \%$ and $3-53 \%$, respectively. ${ }^{13}$ This might be due to the fact that prevalence and profile of intestinal protozoa parasite infection vary widely among countries and within countries. ${ }^{14}$ This variation might be due to difference in degree of level of sanitation, adequate medical care, availability and access to safe drinking water supplies and health care as well as prevailing climatic and environmental condition. ${ }^{15}$ heavy infection with E. histolytica and G. lambila are known to affect childhood health previous studies have revealed that moderate to heavy infection with $E$. histolytica could result in chronic dysentery commonly known as amoebic dysentery, iron deficiency anemia, growth and mental impairment. ${ }^{16}$

\section{Conclusion}

The finding of this study shows the prevalence of intestinal protozoan parasitic infection in Hawassa city administration millennium health center. From the result, a total of eighty ninethousand, four-hundred, twenty-three peoples were examined for various intestinal protozoan parasitic infections in test. From those, the overall prevalence of an infection among patients, thirty ninethousand, eight hundred, ninety-five $(44.61 \%)$ were positive to intestinal protozoa. From these the most common intestinal protozoan parasitic infections were Entamoeba histolytica and Giardia lambila. Entamoeba histolytica was the highly prevalent 22951(57.53\%) and Giardia lambila was the next prevalent 16944(42.47\%) intestinal protozoan parasitic species. An overall age respective study of less than 10 years was highly affected group $(22.98 \%)$ and greater than 50 years old were the least effected group $(16.75 \%)$. From the result, the sex related study show that males were highly affected than females. Its distribution was $(50.98 \%)$ of males and $(40.02 \%)$ of females respectively.

\section{Recommendation}

Based on the present findings, the following recommendation can be forwarded. To minimize or inhibit the spread and impact of Entamoeba histolytica, the following actions should be performed:

I. Providing the basic education for patients particularly for those in rural areas and improving health facility will minimize the risk of intestinal protozoa parasite infection.

II. Governmental and nongovernmental organizations, cultural and religious leaders and other members of society should coordinate effectively to minimize or inhibit its spread and impact by providing enough health services to infected individuals.

Giving awareness to the people who do not know about the means of transmission and its impact to:

a) Build and use enough toilette properly.

b) Treat drinking water by boiling or filtration prior to drinking.

c) Prepare food free of contamination with feces.

\section{Acknowledgements}

None.

\section{Conflict of interest}

The author declares that there is no conflict of interest.

\section{References}

1. Haileayesus Adamu, Beyene Petrose. Intestinal protozoan infection among HIV positive persons with and without antiretroviral treatment (ART) in selected ART center in Adama, Afar and Dire Dawa, Ethiopia. Ethiop J Health Dev. 2009;23(2):133-140.

2. Garcia LS. Diagnostic medical Parasitology. 4th ed. USA: ASM press; 2001. p. 6-59.

3. WHO. Intestinal protozoan infections are the major disease of common public health problems throughout the world. 1994.

4. Zeibig EA. Clinical parasitology: A practical approach. USA: W.B. Sounders Company; 1997. p. 320. 
5. Abinet Alemayehu, Assefa Getachew, Alemu Tadesse. Socio-Economic Profile. 7th ed. Ethiopia: Hawassa city administration; 2014. p. 6-62.

6. Gibson RS, Abebe Y, Hambidge KM, et al. Inadequate feeding Practices and impaired growth among children from subsistence farming households in Sidama, Southern Ethiopia. Matern Child Nutr 2009;5(3):260-275.

7. WHO. Giardia lambila is the protozoan parasite that infects wide array of vertebrates including human. 2004.

8. Odikamnoro OO, Ikey IM. The prevalence of common intestinal Nematode Infections among primary school children in kpirikpiri community in Abakiliki. 28thAnn conf. Niger SOC parasitology. 2004;20:79.

9. Flores JG, Esteban RAS, Mas-coma ST. Soil transmitted helminthes infection at very high altitude in Bolivia. Trans $\mathrm{R}$ SOC Trip Med Hug 2001;95(3):272-277.

10. Abebe A, Yitayal S, Gebeyaw. Opportunistic and other intestinal protozoa among HIV/AIDS patient attending Gambia higher clinic in Bahar Dar city, North west Ethiopia. Asian Pacific J Trip Med. 2011;661-665.
11. Udeeh E, Giselle N, Popova D, et al. the prevelance of intestinal protozoan in HIV/AIDS patient in Abuja, Nigeria. Science World Journal. 2008;3(3):1-4.

12. Tadesse G. Patterns of Infection by Intestinal parasites at mendida Town Northern Ethiopia. Proceedings of 38th Ethiopian medical Association (EMA) annual medical conference. Ethiopia: Addis Ababa; 2002.

13. Amare Mengistu, Solomon Gebreselasie, Tesfaye kassa. Prevalence of intestinal parasitic infection on among Urban dwellers in south west Ethiopia. Ethiopia J Health Dev. 2007;21(1):12-17.

14. Belinelo VJ, Milaneze BA, Rosa AB. Intestinal parasite in students 10 to 15 years of school of saoMateus periphery, ES, Brazil. European Journal of Scientific Research. 2011;53:171-178.

15. WHO. Report on the WHO informal consultation on the use of chemotherapy for the control of morbidity due to soil-transmitted nematodes in humans. Division of the control of tropical diseases, WHO, Geneva. 1996; p. 54.

16. Kloos H, Tesfayohanis TM. Intestinal parasite in Ethiopia. In: Kloos H, editor. Ecology of health and disease in Ethiopia. USA: West view press; 1993. p. 223-225. 